Family Profile No. 5, 2020

\title{
Age at Entry into Motherhood and Mothers' Sociodemographic Characteristics, 2015-2018
} Author: Lisa Carlson

In the U.S., women are entering motherhood at older ages, with the age at first birth rising from a mean of 21.4 in 1970 to 26.8 in 2017 (FP-18-25). Women who have first births at younger ages differ on a range of characteristics compared to women who become mothers at later ages, and maternal age is linked to children's well-being (Gibson-Davis \& Rackin, 2014; Brown, Stykes, \& Manning, 2016; Rackin \& Gibson-Davis, 2018). This profile uses the Current Population Survey's 2018 June Fertility Supplement to identify mothers who had a first birth between 2015 and 2018. Education level, race/ethnicity, and union status of mothers are compared across three groups classified by age at first birth: younger mothers (less than 24 years old), mid-range age mothers ( 24 to 29 years old), and older mothers (30 years or older). Additional profiles using the June Fertility Supplement analyze trends in completed family size among women aged 40-44 by education and race/ethnicity (FP-20-04) and by union status (FP-20-03).

\section{Education}

Women with higher levels of education most often are older at first birth. Education was lowest among mothers with early first births ( $<24$ years old) and highest among mothers who were older (aged 30+) at the age of their first birth.

- While most mothers who were younger at first birth ( $<24$ years old) had earned at least a high school diploma, $13 \%$ had not. Less than one-tenth $(6 \%)$ of young mothers had at least a bachelor's degree. The most common educational level was a high school diploma, at just under half (46\%) of younger mothers.

- Mothers experiencing a first birth at the mid-range (ages 24-29), most often as a bachelor's degree or more (43\%). Nearly a third had some college, and onefifth had a high school education.

- Education levels were highest among first-time mothers who were 30 and older with the majority of mothers in this group having a bachelor's degree or more (69\%).
Figure 1. Maternal Education by Age at First Birth, 2015-2018

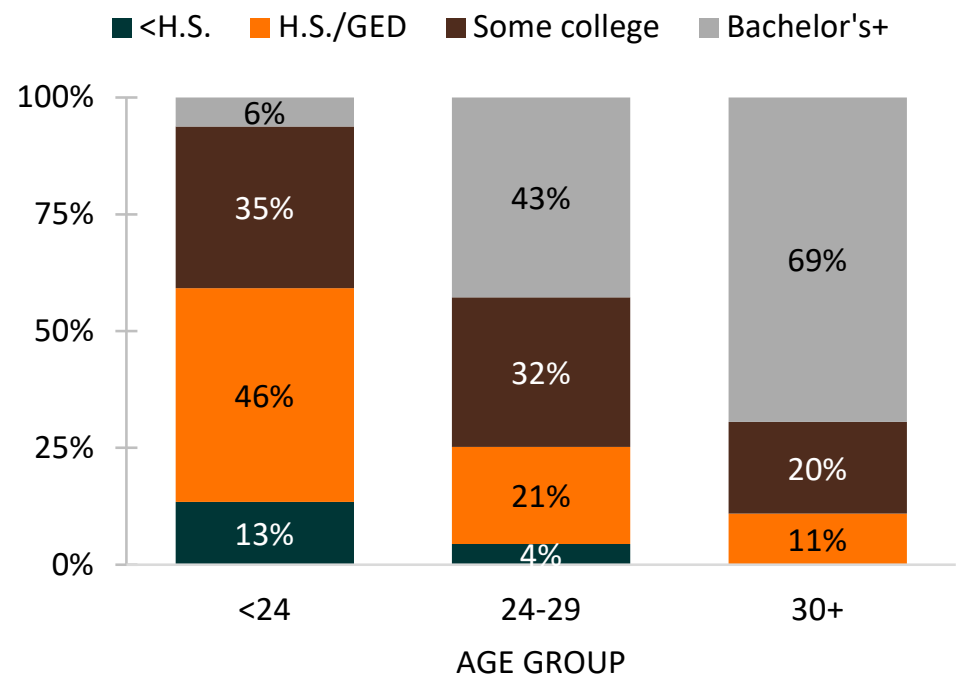

Source: NCFMR analyses of Current Population Survey, June 2018 Fertility Supplement. Note: for women 30 years old or older at first birth there are too few cases where women had less than a high school diploma; virtually all first-time mothers in this age group had a high school diploma or higher.

\section{Data Sources:}

Flood, S., King, M., Rodgers, R., Ruggles, S., \& Warren, J. R. (2019) Integrated Public Use Microdata Series, Current Population Survey: Version 7.0 [dataset]. Minneapolis, MN: IPUMS. https://doi.org/10.18128/D030.V7.0

\section{References:}

Brown, S. L., Stykes, J. B., \& Manning, W. D. (2018) Trends in children's family instability, 1995-2010. Journal of Marriage and Family, 78(5), $1173-1183$. doi.org/10.1111/jomf.12311

Gibson-Davis, C. \& Rackin, H. (2014). Marriage or carriage? Trends in union context and birth type by education. Journal of Marriage and Family, 76(3), 506519. doi.org/10.1111/jomf.12109

Guzzo, K. B., \& Payne, K. K. (2018). Average age at first birth, 1970-2017. Family Profiles, FP-18-25. Bowling Green, OH: National Center for Family \& Marriage Research. https://doi.org/10.25035/ncfmr/fp-18-25

Hemez, P. (2018). Young adulthood: Cohabitation, birth, and marriage experiences. Family Profiles, FP-18-22. Bowling Green, OH: National Center for Family \& Marriage Research. https://doi.org/10.25035/ncfmr/fp-18-22

Hemez, P. (2019). Family formation experiences: Women's median ages at first marriage and first birth, 1979 \& 2016. Family Profiles, FP-19-16. Bowling Green, $\mathrm{OH}$ : National Center for Family \& Marriage Research. https://doi.org/10.25035/ncfmr/fp-19-16

Rackin, H. M. \& Gibson-Davis, C. M. (2016). Social class divergence in family transitions: The importance of cohabitation. Journal of Marriage and Family, 80(5), 1271-1286. doi.org/10.1111/jomf.12522 
Race/Ethnicity

- Greater shares of Hispanic mothers and Black mothers entered motherhood at younger ages than at older ages.

0 The median ages at first birth for Black and Hispanic mothers were 26 and 25 , respectively, compared to almost 28 for White women and women of other races (not shown).

- Younger mothers were disproportionately racial-ethnic minorities. About one-quarter $(27 \%)$ of younger mothers were Hispanics, and $17 \%$ were Black.

- Among mothers having their first birth at mid-range ages (24-29), just over half (55\%) were White, $20 \%$ were Hispanic, and $13 \%$ were Black.

- The majority (62\%) of older first-time mothers (aged 30 or older) were White. Only one in ten older mothers were Black, and $14 \%$ were Hispanic.

\section{Union Status}

The union status of mothers varied according to their age at entry into motherhood.

- Three-fourths of younger mothers (< age 24 at first birth) were unmarried (either single or cohabiting). The most common union status for younger mothers was cohabitation (44\%).

- The majority $(60 \%)$ of mid-range age mothers (ages 24 29) were married at first birth, and a quarter were cohabiting at first birth.

- A large majority of mothers with first births experienced at ages 30 or older were married (81\%). Among older mothers, only $12 \%$ were cohabiting, and even fewer (7\%) were not living with a partner.
Figure 2. Maternal Race/Ethnicity by Age at First Birth, 2015-2018

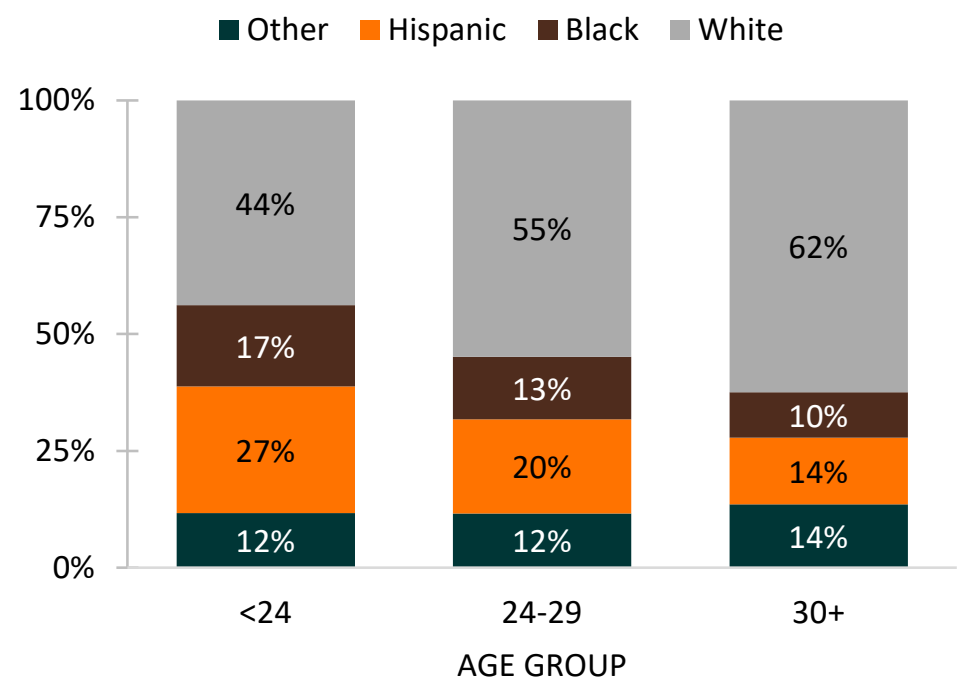

Source: NCFMR analyses of Current Population Survey, June 2018 Fertility Supplement.

Figure 3. Maternal Union Status by Age at First Birth, 2015-2018

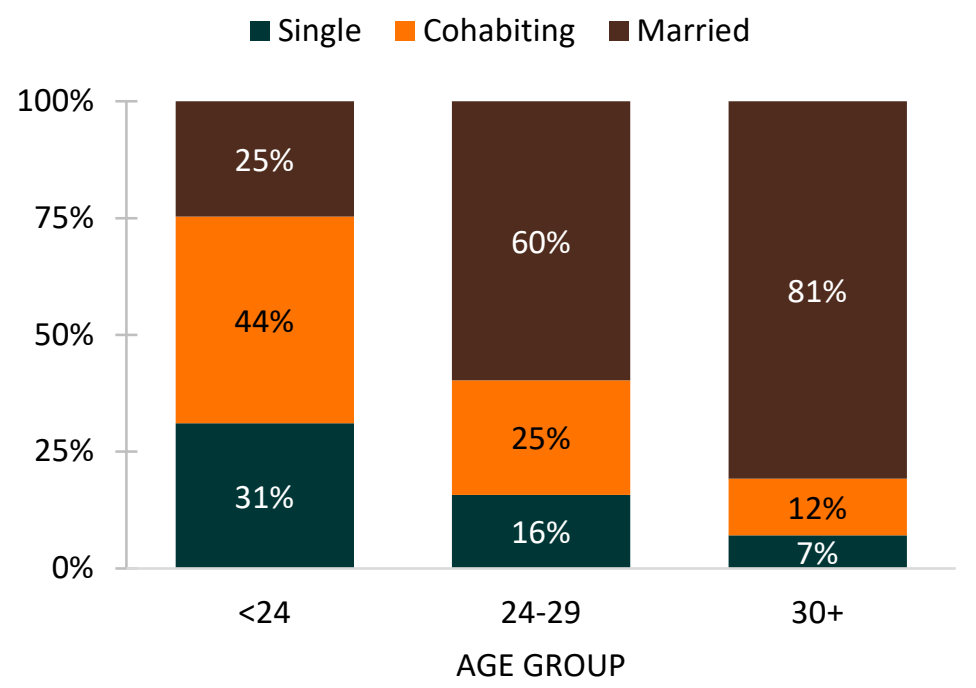

Source: NCFMR analyses of Current Population Survey, June 2018 Fertility Supplement.

\section{Suggested Citation:}

Carlson, L. (2020). Age at entry into motherhood and mothers' sociodemographic characteristics, 2015-2018. Family Profiles, FP17-22. Bowling Green, OH: National Center for Family \& Marriage Research. https://doi.org/10.25035/ncfmr/fp-20-05 